\section{Mathematical tools}

The Mathematics of Diffusion. Second edition. By J. Crank. Pp. viii +414 . (Clarendon: Oxford; Oxford University Press: London, March 1975.) £12.50.

This volume could be regarded more as a tool kit than a book. Most of the content comprises a collection of mathematical methods for the analysis of diffusion problems, together with the solutions of the appropriate equations for many common situations. As mathematical results tend to be less transient than those of most other sciences, the bulk of the book is unchanged from the first (1955) edition, save for the addition of new references. In this new edition there are many cross-references to its alter-ego The Conduction of Heat in Solids by Carslaw and Jaeger; the latter volume presents a wider range of solutions to the diffusion equations and Crank has chosen those which are most appropriate to diffusion problems.

New material in this edition includes a chapter on non-Fickian diffusion, which provides an interesting review of solvent diffusion in glassy polymers, but it is somewhat out of place in this book in that it is inconclusive. A new chapter on diffusion in heterogeneous media is particularly timely as composite materials have become so widely used. The chapter

\section{ATLA ABSTRACIS}

(Alternatives to Laboratory Animals)

is published twice yearly and contains current information on replacement techniques. Coverage includes a variety of disciplines in a wide selection of world scientific literature.

Have you a copy in your Library? If not a free specimen will be sent on request.

\section{FRAME, 312a Worple Road, London SW20 8QU}

(Fund for the Replacement of Animals in Medica Experiments)

(Registered Charity No. 259464 England)

Tel : $01-9461450$ on numerical methods has been extensively revised to allow for the dramatic effects of developments in digital computers. Sadly, however, several diagrams of quaint analogue calculating machines have been lost in the process. This chapter is too brief, given that it is now often easier to compute a numerical solution than to derive the analytical solution, if one is not too proud. The challenge to a book of this kind is to provide enough detail to allow the average user to write the programme without consulting other sources. Crank dodges this challenge and simply gives a well referenced outline of the available methods.

This volume is a worthy successor to the first edition and will undoubtedly become an indispensable reference source for all who are concerned with diffusion problems.

P. D. Calvert and N. C. Billingham

\section{Dynamic patterns}

Dynamic Patterns of Brain Cell Assemblies. By A. K. Katchalsky, V. Rowland and R. Blumenthal. Pp. 187+ viii. (MIT Press: Cambridge, Massachusetts, and London, 1974.) \$15.00; $£ 7.50$.

WHAT is meant by "dynamic patterns"? In the present context the expression implies the idea that systems are made up of a complex hierarchy of smaller and larger "flow patterns" in which "things" are self-maintaining features of the flows. The concept also implies that the flow patterns can undergo sudden flip-over alterations, or translations, to new stable self-maintaining arrangements. Thus, one could say that the world is made up of complexes of movements, or dynamic patterns.

How important are these dynamic patterns? Are they merely biomathematicians' fantasies -intellectual toys-or are they of fundamental significance in biology? This book reports on a Neurosciences Research Programme Work Session, held in 1972, when various neuroscientists came together to consider the phenomenology of dynamic patterns and their relevance to neurobiology. Examples of dynamic patterns are presented from many fields including biology - the cellular structure that develops in a heated dish of spermaceti oil, selfmaintaining cloud patterns, the well known Beloussov-Zhabotinsky reaction, and so on. Indeed, the invocation of dynamic patterns, or "cooperative nonequilibrium phenomena" is fashionable in fields as diverse as molecular interactions, developmental biology and sociology. My feeling is that these phenomena are likely to be of great significance, particularly for developmental biology and neurophysiology, and this book provides a useful introduction for non-specialists.

R. M. Gaze

\section{Global tectonics} and fossil fuel

Petroleum and Global Tectonics. Edited by Alfred G. Fischer and Sheldon Judson. Pp. xii +322 . (Princeton University Press: Princeton and London, May 1975.) Cloth, £8.70; paper, $£ 4.45$.

Ar the present time the surest way to get any geological manuscript into print is to postscript the title '... and Global Tectonics'.

This volume, Petroleum and Global Tectonics, contains nine papers presented at a conference held in 1972 to honour Hollis D. Hedberg of Princeton University. The papers cover plate tectonics (Bullard), heat flow and vertical movements of the crust (Morgan), the origin and growth of basins (Fischer), rift valley basins and the sedimentary history of trailing continental margins (Kinsman), the petroleum and plate tectonics of the southern Red Sea (EXXON), marine sediments, geosynclines and orogeny (Curray), geochemical formation of oil (Erdman), geothermal gradients, heat flow, and hydrocarbon recovery (Klemme), and the distribution and geological characteristics of giant oil fields (Moody).

The idea of choosing a conference theme of interest to both academic and industrial geologists is highly commendable. But the academic and industrial authors seem to have been mutually embarrassed and to have been uneasy about the theme. Sir Edward Bullard thought the impact of plate tectonics on petroleum exploration was "rather weak" (p. 17), and Moody was similarly perplexed: 'I have some difficulty in trying to relate giant oil fields to the "New Global Tectonics" per se' (p. 314).

The net result is that most authors have gone off and 'done their own thing', either writing about global tectonics or about petroleum, but seldom about both.

It is only in the papers by the Exxon group, Klemme and Moody, that the two topics of petroleum and global tectonics are actually integrated, and very successfully so. The material for these three contributions is largely taken from back numbers of the Oil and Gas Journal and from the Bulletins and Memoirs of the American Association of Petroleum Geologists.

The volume does include, however, several excellent papers on sedimentary basins, geothermal gradients, modern marine sedimentary environments, rift valleys and the origin of oil.

The book is attractively produced and the illustrations are ample and clear.

R. C. Selley 